\title{
RECEPÇÃO “CALOUROSA": CONHECIMENTOS, EXPECTATIVAS E OPINIÕES DE INGRESSANTES DO CURSO DE LICENCIATURA EM CIÊNCIAS BIOLÓGICAS
}

\author{
G. M. LIMA ${ }^{1}$, T. A. ALVES ${ }^{1}$, M. A. DIAS ${ }^{1}$, D. C. ESTRELA ${ }^{1}$, C. G. C. LEMES $^{1}$, R. NUNES ${ }^{1}$, I. R. PEREIRA ${ }^{1}$, K. R. A \\ SANTOS $^{1}$, M. L. TAVARES ${ }^{1}$, G. MALAFAIA ${ }^{2}$, A. L. S. CASTRO ${ }^{2,3}$ \\ 1,3 Instituto Federal Goiano - NPCBA. \\ andre.castro@ifgoiano.edu.br
}

Artigo submetido em março/2013 e aceito em fevereiro/2014

\section{RESUMO}

Este estudo objetivou relatar de forma crítica e reflexiva a atividade de recepção dos ingressantes do curso de Licenciatura em Ciências Biológicas e avaliar seus conhecimentos, expectativas e opiniões. A recepção foi realizada no primeiro semestre letivo de 2012, por alunos do Programa de Educação Tutorial (PET), envolvendo alunos do curso de Licenciatura em Ciências Biológicas do IF Goiano - Câmpus Urutaí e ofereceu atividades diversas de caráter informativo, integrativo e de estímulo à permanência no curso. Após a atividade de recepção foi aplicado um questionário para um feedback e planejamento de ações futuras. A atividade foi avaliada por $46 \%$ dos calouros como "excelente" e $46 \%$, como "boa". Para $71 \%$ dos ingressantes, a atividade contribuiu para a interação com outros discentes, $76,9 \%$ disseram que foi uma motivação para ingressar no PET. De modo geral, conclui-se que a recepção foi importante para a adaptação dos ingressantes à vida acadêmica e para minimizar as possíveis dificuldades encontradas pelos calouros

PALAVRAS-CHAVE: Calouros; Grupo PET; Interação.

\section{FRIENDLY RECEPTION: KNOWLEDGE, EXPECTATIONS AND OPINIONS FROM FRESHMAN STUDENTS OF BIOLOGICAL SCIENCES}

\begin{abstract}
The aim of this study was to critically and reflexively describe the reception activity of freshman students of Biological Sciences course and their knowledge, expectations and opinions. The reception occurred in the first semester in 2012, organized by students of the Tutorial Education Program, involving students of Biological Sciences course from IF Goiano - Campus Urutaí and was offered different informative activities, integrative and encouragement to remain in the course. A questionnaire was applied after reception activity for
\end{abstract}

feedback and planning future actions. The activity was evaluated by $46 \%$ of new students as "excellent" and $46 \%$ as "good". For $71 \%$ of freshmen, the activity contributed to the interaction with other students, $76.9 \%$ said that was a motivation for ingress in the TEP. Overall, it is concluded that the reception was important for the adaptation of freshmen to academic life and to minimize possible difficulties encountered by freshman students.

KEYWORDS: Freshman; PET Group; Interaction. 


\section{INTRODUÇÃO}

As políticas públicas educacionais no Brasil têm mudado o cenário tanto das instituições públicas de ensino quanto das instituições privadas, culminando na expansão da oferta de vagas para alunos nas últimas décadas. Nesse cenário, destaca-se a expansão do ensino superior, com programas como a Universidade Aberta do Brasil (UAB), o Programa de Reestruturação e Expansão das Universidades Federais (Reuni) e o Programa Universidade para Todos (ProUni), conforme apontam Pereira \& Silva (2010). Contudo, o aumento de vagas a alunos para os cursos de graduação não garante o ingresso dos alunos nas Instituições de Ensino Superior (IES), nem tampouco sua permanência ou conclusão do curso.

Na contramão do aumento da oferta de vagas no ensino superior do Brasil está a evasão escolar. Segundo Silva-Filho et al. (2007), a média de evasão nos cursos superiores do Brasil é $22 \%$, destoando muito de países como o Japão, o qual apresenta uma das menores taxas de evasão mundial (7\%). Assim, é preciso investir tanto em pesquisas que compreendam as causas da evasão escolar, quanto em estratégias que reduzam esses indicadores negativos. Nesse sentido, os programas do governo federal que investem em bolsas de estudo para alunos podem contribuir para a permanência do aluno nos cursos superiores, assim como para a adoção de outras iniciativas que contribuam para a melhoria da qualidade de ensino.

Um dos programas do Ministério da Educação que oferece bolsas a alunos dos cursos superiores é o Programa de Educação Tutorial (PET), criado em 1979 pela CAPES e regulamentado pela Lei 11.180, de 23 de setembro de 2005 (Brasil, s.d.). O PET constitui-se em uma modalidade de investimento acadêmico em cursos de graduação que tem como objetivo melhorar a qualidade do ensino, por meio de grupos tutoriais de aprendizagem (Brasil, s.d.). Xavier e Goulart (2008) ressaltam que a proposta trazida pelos grupos PET à comunidade universitária estabelece um divisor importante entre eles e qualquer outro programa de formação acadêmica, na medida em que são trabalhados de forma articulada os 3 pilares do saber acadêmico: ensino, pesquisa e extensão.

Apesar da inegável contribuição da existência de um grupo PET em uma IES, tanto para o curso quanto para a instituição, inúmeros desafios aparecem tanto nos momentos de planejamento, quanto na execução e avaliação das atividades dos grupos PET. Entre os principais desafios estão a motivação dos alunos para o ingresso no PET, a permanência no curso, a diminuição dos índices de evasão e a superação da falta de interesse para atuação profissional na área educacional.

Segundo Cunha e Carrilho (2005), o ingresso dos alunos no ensino superior é marcado por inúmeros desafios, tanto pela adaptação ao curso, quanto pela transição entre a adolescência e a vida adulta. Ademais, os estudantes que conseguem integrar-se acadêmica e socialmente desde o ingresso à IES têm maior chance de crescimento intelectual e pessoal (Teixeira et al., 2008). Dessa forma, uma adaptação bem sucedida ao ensino superior, especialmente no primeiro ano acadêmico, é um preditor importante da persistência e sucesso dos estudantes além de poder determinar os padrões de desenvolvimento ao longo da vida universitária e profissional (Cunha e Carrilho, 2005). Assim, é papel das IES implementar programas de atenção especial a alunos 
recém-chegados, de forma a favorecer a adaptação acadêmica e minimizar os impactos negativos desta transição (Cunha e Carrilho, 2005), podendo inclusive reduzir a evasão e retenção escolar.

Um dos grupos PET aprovados pelo MEC/SESu, o qual está ligado ao curso de Licenciatura em Ciências Biológicas do Instituto Federal Goiano (IF Goiano) - Câmpus Urutaí é o PET Bio Urutaí. O referido grupo iniciou seus trabalhos em dezembro de 2010 e desde então vem realizando anualmente uma recepção dos acadêmicos ingressantes do curso de Licenciatura em Ciências Biológicas, iniciando no primeiro dia letivo do semestre. A atividade é planejada e executada pelos petianos e intitulada "Recepção calourosa", com a filosofia de acolher os ingressantes de forma prazerosa, formativa/informativa, a fim de contribuir para a adaptação do calouro à vida acadêmica. A cada ano o planejamento desta atividade leva em conta os desafios do aluno recém-chegado na IES, os desafios da instituição em relação à evasão do curso, bem como a filosofia e os desafios do PET.

Nesse sentido, o presente estudo avaliou o conhecimento prévio de ingressantes sobre o curso de Licenciatura em Ciências Biológicas e uma atividade de recepção realizada com os referidos alunos. Acredita-se que este trabalho possa subsidiar a realização de atividades para adaptação do ingressante à vida acadêmica em outras IES do Brasil.

\section{MATERIAL E MÉTODOS}

A recepção dos calouros do curso Licenciatura em Ciências Biológicas foi planejada e executada pelo PET Bio Urutaí, em parceria com a Coordenação de Curso e alunos do Programa Institucional de Bolsas de Iniciação à Docência (PIBID), subprojeto de Ciências Biológicas - do IF Goiano - Câmpus Urutaí. As atividades foram realizadas nos dois primeiros dias do primeiro semestre letivo de 2012 (06 e 07 de fevereiro), totalizando 8 h de execução.

Desde sua chegada, os calouros foram recebidos pelos alunos petianos e convidados a se dirigirem ao auditório do IF Goiano - Câmpus Urutaí, para início da atividade. Uma dinâmica de boas vindas foi realizada de forma a permitir a apresentação individual de todos os presentes e promover a interação entre os calouros e destes com os alunos veteranos. Após a dinâmica os calouros foram convidados a conhecer todas as dependências e instalações do câmpus, sob a supervisão dos petianos, os quais foram explicando o funcionamento de cada setor e os serviços oferecidos.

No segundo dia de recepção foram realizadas diversas apresentações, com o uso de datashow, sobre: o histórico da IF Goiano - Câmpus Urutaí, as diferenças entre licenciatura e bacharelado, o perfil do egresso dessas modalidades, as áreas de atuação do profissional biólogo (educação, botânica, zoologia, saúde, ecologia, genética), o PET, o PIBID, as bolsas de estudos oferecidas na instituição e outras oportunidades de atuação em pesquisa do IF Goiano - Câmpus Urutaí. As apresentações tiveram o intuito de orientar para as diferentes possibilidades de atuação do ingressante no âmbito universitário.

Foi entregue a cada ingressante um "Manual do Calouro - 2012", elaborado pelo PET Bio Urutaí, que continha informações como: histórico da instituição e os cursos oferecidos, oportunidades e serviços oferecidos no câmpus (refeitório, biblioteca, academia, reprografia, laboratórios etc), dicionário de verbetes e siglas e o calendário acadêmico vigente. A atividade foi 
finalizada com a oferta de um lanche para confraternização e a realização de apresentações musicais por alunos e servidores do câmpus.

Após a recepção, os ingressantes (2012_1) responderam um questionário que continha 12 questões, entre elas abertas, fechadas e mistas. O questionário (anônimo e aplicado em sala de aula) buscou avaliar o cumprimento dos objetivos previstos pela referida atividade, o conhecimento prévio sobre a Licenciatura em Ciências Biológicas, bem como conhecer possíveis impactos da atividade na vida acadêmica dos alunos, conforme o Quadro 1 . As questões referentes à Licenciatura em Ciências Biológicas visavam avaliar o quanto o calouro conhecia sobre o curso escolhido. Participaram da recepção 75 alunos do curso de Licenciatura em Ciências Biológicas, sendo 20 destes calouros. O questionário investigativo foi respondido por $65 \%(n=13)$ dos calouros. Os dados obtidos foram analisados de forma quantitativa, por meio do cálculo de percentagens (frequência relativa).

Quadro 1: Questionário aplicado aos ingressantes do curso de Licenciatura em Ciências Biológicas do Instituto Federal Goiano - Câmpus Urutaí

1) De maneira geral, como você avalia a forma como foi recebido pelo PET Bio Urutaí?

2) A recepção organizada pelo PET Bio contribuiu para sua interação com os colegas de classe e de outras turmas da Biologia?

3) As apresentações realizadas pelos alunos do PET Bio contribuíram para um maior conhecimento das áreas da Biologia e da atuação do biólogo?

4) Antes da recepção dos calouros você sabia a diferença entre Licenciatura e Bacharelado em Ciências Biológicas?

5) Antes da recepção você sabia da existência do PET Bio Urutaí?

6) Você tinha conhecimento sobre as bolsas para alunos, disponíveis no IF Goiano - Câmpus Urutaí?

7) A recepção dos calouros o motiva a participar do PET Bio como aluno bolsista?

8) Como você avalia o Manual do Calouro que recebeu?

9) Você já utilizou alguma informação que aprendeu ao ler o Manual do Calouro?

10) Qual informação você sugere para ser incluída no Manual do calouro 2013?

11) Você conhecia as dependências do IF Goiano visitadas durante a atividade de recepção?

12) A atividade de recepção realizada pelo PET Bio Urutaí foi um fator de motivação para a sua permanência no curso?

\section{RESULTADOS E DISCUSSÃO}

Pode-se dizer que num primeiro momento, os calouros (2012_1) do curso de Licenciatura em Ciências Biológicas do IF Goiano - Câmpus Urutaí demonstraram certo espanto e apreensão em relação às variadas informações que foram expostas, especialmente aquelas ligadas ao funcionamento da instituição, do grupo PET e às possíveis áreas de atuação do biólogo (licenciado ou bacharel). Para Bellodi (2004), as reações de espanto, insegurança e apreensão são consequência direta da participação dos alunos em um novo ambiente no qual o conhecimento precisa ser construído de maneira crítica e por meio de várias discussões, diferente dos ambientes vivenciados nos cursinhos preparatórios de vestibulares ou ensino médio, nos quais a aprendizagem, muitas vezes, já vem "pronta" ou encontra-se em apostilas e outros recursos didáticos pré-elaborados. 
A apresentação individual dos petianos (alunos e tutor), professores do curso de Licenciatura em Ciências Biológicas e dos bolsistas do subprojeto Ciências Biológicas do PIBID - IF Goiano foi marcada por momentos de descontração e explicações sobre diversos aspectos ligados à instituição e aos programas PET e PIBID. Pode-se dizer que esses momentos mostraramse esclarecedores e veículos importantes para socializar com os novos acadêmicos conceitos como o de pesquisa, ensino e extensão, além de valorizar a aprovação no vestibular pelos calouros, mostrando a real amplitude de atuação da carreira escolhida.

Os calouros demonstraram-se receptivos, interessados, participativos, e principalmente curiosos quanto às atividades realizadas pelo grupo PET Bio - Urutaí. Além disso, notou-se também uma disposição dos calouros para participarem das oportunidades oferecidas pelo curso. Estas observações foram constatadas pelo número de perguntas realizadas durante e após a apresentação, pelas visitas aos diversos setores da instituição e pela participação dos alunos recém-ingressos nas dinâmicas promovidas pelo grupo PET Bio - Urutaí durante a recepção.

Em relação aos resultados da aplicação do questionário, a primeira questão avaliou como os alunos classificaram a atividade desenvolvida, considerando aspectos diversos, como dinâmica interativa, importância da atividade, receptividade, dentre outros. Observou-se que, de uma maneira geral, que a "Recepção calourosa" foi bem avaliada pelos estudantes, uma vez que $46,15 \%(n=6)$ a classificaram como "excelente", 46,15\% (n=6), como "boa" e apenas 7,5\% ( $n=1)$ como "regular". Ressalta-se que nenhum dos respondentes avaliou a atividade como "péssima" ou "ruim", indicando que, independente de atingir ou não os objetivos propostos, a atividade foi positiva.

Segundo os calouros, a recepção contribuiu positivamente para a interação com acadêmicos da mesma turma e de outras turmas do curso, conforme pode ser observado na Tabela 1. Aproximadamente $77 \%$ da avaliação realizada pelos estudantes foram enquadradas nas categorias "boa" ou "excelente".

Tabela 1: Avaliação dos calouros sobre a contribuição da atividade de recepção para a interação com outros acadêmicos.

\begin{tabular}{cc}
\hline Categoria de respostas & \% de respondentes \\
\hline Péssima & 0 \\
Ruim & 0 \\
Regular & 15,38 \\
Bom & 30,76 \\
Excelente & 46,15 \\
\hline
\end{tabular}

Atividades de recepção aos calouros, sem o uso de violência e intimidação, têm sido conduzidas por diversos grupos PET no Brasil, a exemplo da atividade relatada por Vasco et al. (2012). Nessas atividades, são recorrentes a observação da promoção de interações positivas entre os discentes dos cursos, a oportunização aos recém-ingressantes de desenvolvimento de atividades acadêmicas diversificadas, maior conhecimento sobre o curso e a instituição, assim como melhorias nas relações interpessoais entre os alunos. Além disso, por meio dessas atividades almeja-se concretizar, desde cedo, o espírito universitário nos recém-chegados, estimulando o companheirismo e o interesse pelo curso e por todas as atividades realizadas na instituição. 
As apresentações sobre as áreas das Ciências Biológicas, bem como a atuação do biólogo em cada área, realizadas pelos petianos, na visão dos calouros, contribuíram para um melhor conhecimento sobre futuras atuações profissionais. A Tabela 2 mostra que mais de $70 \%$ das avaliações realizadas pelos alunos foram enquadradas nas categorias "boa" e "excelente".

Tabela 2: Avaliação dos calouros sobre a contribuição das apresentações realizadas pelos alunos petianos sobre as áreas da Biologia e atuação do biólogo.

\begin{tabular}{cc}
\hline Categoria de resposta & \% de respondentes \\
\hline Péssima & 0 \\
Ruim & 0 \\
Regular & 15,38 \\
Bom & 30,76 \\
Excelente & 46,15 \\
\hline
\end{tabular}

Sobre esse aspecto, Ribeiro (2003) destaca que o jovem que ingressa nas IES, no momento da escolha profissional, muitas vezes, não possui acesso às informações sobre a carreira. Essa falta de conhecimento pode levar a problemas futuros, como o distanciamento entre o que o aluno espera do curso e o que o curso oferece. Nesse sentido, entende-se que a estratégia adotada de orientação sobre as áreas de atuação do biólogo logo nos primeiros dias de aula pode minimizar esse distanciamento supracitado e despertar no calouro o sentimento de pertencimento à instituição e maior vínculo com a carreira.

O presente estudo também investigou se os calouros (2012_1) possuíam conhecimentos sobre as diferenças entre as modalidades licenciatura e bacharelado, antes do ingresso no curso. Os dados evidenciam que $84,6 \%(n=11)$ dos discentes disseram que conheciam, antes da atividade receptiva, as diferenças entre as modalidades licenciatura e bacharelado do curso de Ciências Biológicas. Contudo, alguns recém-ingressantes não conheciam as diferenças entre licenciatura e bacharelado. Isto pode indicar, em princípio, certa divergência entre o perfil do profissional que será formado no curso e a intenção inicial do discente, o que pode ao longo do seu processo formativo causar-lhe frustação e levá-lo ao abandono do curso. Embora parte deste problema tenha possivelmente causas na Educação Básica, por falta de orientação vocacional e conhecimento sobre as profissões, a situação pode ser minimizada na medida em que o aluno é orientado sobre suas reais possibilidades de atuação, aspecto este contemplado na atividade de "Recepção calourosa". Nesse sentido, Cunha \& Carrilho (2005) endossam o argumento de que cabe às IES propiciar a adaptação dos alunos ingressantes e o desenvolvimento das suas potencialidades ao nível máximo.

Os dados do presente estudo apontam ainda o desconhecimento de grande parte dos ingressantes sobre as oportunidades oferecidas pela IES e especificamente pelo curso escolhido. Observou-se, por exemplo, que aproximadamente $69 \%(n=9)$ dos calouros não tinham qualquer conhecimento sobre o PET e $15 \%(n=2)$ não tinham qualquer conhecimento sobre as bolsas de estudo oferecidas na instituição. Estes dados apontam para o fato de que por mais que os programas do governo federal implementem bolsas de estudos para alunos, aliadas à oportunidades de formação acadêmica complementar, a divulgação não tem atingido o públicoalvo. Nesse caso, pode-se dizer que o conhecimento da sociedade (incluindo alunos do ensino médio que almejam ingressar no ensino superior) sobre a possibilidade de concessão de bolsas de estudos ou de assistência estudantil, aliadas a uma formação acadêmica mais sólida e ampla 
que envolva pesquisa, ensino e extensão, certamente pode atuar como mais uma motivação ao seu ingresso numa IES.

Para 76,9\% ( $n=10)$ dos alunos entrevistados, a atividade de recepção realizada foi avaliada como um fator motivador para suas participações em editais de seleção para ingresso no PET e $84,61 \%(n=11)$ a consideraram como motivadora para a permanência no curso de Licenciatura em Ciências Biológicas. Estes dados são importantes tanto para a superação de desafios do PET Bio Urutaí, quanto para os desafios institucionais (incluindo a gestão do curso de Licenciatura em Ciências Biológicas), no sentido de reduzir a evasão e a retenção escolar. Segundo Reis et al. (2008), parte dos problemas detectados em um curso de Ciências Biológicas é a insatisfação do acadêmico com sua formação. Dessa forma, conforme ressalta Ruiz (2003), a motivação do aluno no ensino superior depende diretamente das atividades acadêmicas do seu interesse, que pode ser potencializado pelo seu ingresso e permanência em programas educacionais (como o PET) que fazem parte do curso escolhido.

Vale destacar que a permanência no curso, as reprovações e a evasão escolares devem ser avaliados periodicamente, em médio e longo prazo, para conclusões mais seguras. Porém, frente a dados nacionais preocupantes de evasão escolar no ensino superior, políticas, estratégias ou atividades que vislumbrem maior envolvimento dos acadêmicos e funcionem como fatores motivadores para permanência do aluno no curso merecem ser desenvolvidas e valorizadas.

\section{CONCLUSÃO}

A atividade de recepção atingiu seus objetivos e mostrou-se como uma iniciativa que pode contribuir precipuamente para a adaptação dos ingressantes à IES, ao curso e à vida acadêmica, em um período importante e decisivo para o futuro profissional. Os dados apontam para que a atividade continue sendo realizada anualmente e estimulam a implementação de melhorias na recepção, a fim de favorecer a adaptação do calouro à vida acadêmica desde o seu primeiro dia de aula, visando ainda maior envolvimento com a carreira e sucesso profissional.

\section{REFERÊNCIAS BIBLIOGRÁFICAS}

1. BELLODI, P.L. O programa tutores e a integração dos calouros na FMUSP. Revista Brasileira de Educação Médica, v.28, n.3, p.204-214, 2004.

2. Brasil. Ministério da Educação. Secretaria de Educação Superior. Programa de Educação Tutorial - PET: manual de orientações básicas. Brasília: MEC, s.d. 25 p.

3. CUNHA, S. M., CARRILHO, D.M. O processo de adaptação ao ensino superior e o rendimento acadêmico adaptação e rendimento acadêmico. Psicologia Escolar e Educacional, v.9, n.2, p.215-224, 2005.

4. FILHO, R.L.L.S., MOTEJUNAS, P.R., HIPÓLITO, O., LOBO, M.B.C.M. A evasão no ensino superior brasileiro. Cadernos de Pesquisa, v.37, n.132, p.641-659, 2007.

5. PEREIRA, T.I., SILVA, L.F.S.C. As políticas públicas do ensino superior no Governo Lula: expansão ou democratização? Revista Debates v.4, n.2, p.10-31, 2010.

6. REIS, M.F., REIS M.F. Acadêmicos de Ciências Biológicas: investigação sobre formação 
docente. Revista Saúde e Pesquisa, v.1, n.2, p. 103-109, 2008.

7. RIBEIRO, M.A. Demandas em Orientação Profissional: um estudo exploratório em escolas públicas. Revista Brasileira de Orientação Profissional, v.4, n.1/2, p. 141-151, 2003.

8. RUIZ, V.M. Motivação na universidade: uma revisão da literatura. Revista Estudos de Psicologia, v.20, n.2, p.15-24, 2003.

9. TEIXEIRA, M.A.P., DIAS, A.C.G., WOTTRICH, S.H. Adaptação à universidade em jovens calouros. Revista Semestral da Associação Brasileira de Psicologia Escolar e Educacional (ABRAPEE), v.12, n. 1, p.185-202, 2008.

10. VASCO, V.R., PEDROSO, C.F., ROSA, F.C.M., MOREIRA, I.A., BATISTA,K.C.O., ESTEVES, L.V., PESSOA, M.A., FERNANDES, R.R., SILVA, R.E., AVELAR, S.C., MAMED, S.N., SOUZA, T.P., BARBOSA, M.A. Recepção dos calouros: projeto de ensino desenvolvido pelo grupo PE (Programa de Educação Tutorial) de enfermagem da Universidade Federal de Goiás. Disponível em: http://www.sbpcnet.org.br/livro/63ra/conpeex/pet/trabalhos-pet/petvanessa-romeiro.pdf. Acesso em: 20 out. 2012.

11. XAVIER, B.T.L., GOULART, D.F. Ensino, Pesquisa e Extensão consorciados: a fórmula do sucesso do Programa de Educação Tutorial. In: Martins I. L., Ketzer S. M. (Org.). Programa de Educação Tutorial: estratégia para o desenvolvimento da graduação. Programa de Educação Tutorial: estratégia para o desenvolvimento da graduação. Brasília: Brasil Tropical, v.1, p.7173, 2008. 